\section{OPEN ACCESS}

Edited and reviewed by:

Harry W. Schroeder,

University of Alabama at Birmingham,

United States

*Correspondence: Shuyang Yu

ysy@cau.edu.cn

Xiao Yang

yangx@bmi.ac.cn

Yaofeng Zhao

yaofengzhao@cau.edu.cn

${ }^{\dagger}$ Present Address: Tianyi Zhang,

Department of Nutritional Science, Cornell University, Ithaca, NY,

United States

¥These authors have contributed equally to this work

Specialty section:

This article was submitted to B Cell Biology,

a section of the journal

Frontiers in Immunology

Received: 28 November 2018

Accepted: 15 February 2019

Published: 08 March 2019

Citation:

Zhang T, Cheng X, Yu D, Lin F, Hou N, Cheng X, Hao S, Wei J, Ma L, Fu Y, Ma Y, Ren L, Han H, Yu S, Yang $X$ and Zhao Y (2019) Corrigendum: Genetic Removal of the $\mathrm{CH} 1$ Exon Enables the

Production of Heavy Chain-Only IgG in Mice. Front. Immunol. 10:398. doi: 10.3389/fimmu.2019.00398

\title{
Corrigendum: Genetic Removal of the CH1 Exon Enables the Production of Heavy Chain-Only IgG in Mice
}

\begin{abstract}
Tianyi Zhang ${ }^{1+\neq}$, Xueqian Cheng ${ }^{1 \neq}$, Di Yu ${ }^{1 \neq}$, Fuyu Lin $^{2}$, Ning Hou ${ }^{2}$, Xuan Cheng ${ }^{2}$, Shanshan $\mathrm{Hao}^{1}$, Jingjing $\mathrm{Wei}^{1}$, Li Ma ${ }^{1}$, Yanbin $\mathrm{Fu}^{1}$, Yonghe Ma ${ }^{1}$, Liming Ren ${ }^{1}$, Haitang Han ${ }^{1}$, Shuyang Yu ${ }^{1 *}$, Xiao Yang ${ }^{2 *}$ and Yaofeng Zhao ${ }^{1 *}$
\end{abstract}

1 State Key Laboratory of Agrobiotechnology, College of Biological Sciences, National Engineering Laboratory for Animal Breeding, China Agricultural University, Beijing, China, ${ }^{2}$ State Key Laboratory of Proteomics, Beijing Proteome Research Center, National Center for Protein Sciences (Beijing), Beijing Institute of Lifeomics, Beijing, China

Keywords: HcAbs, nanobody, $\mathrm{CH} 1$ domain, mouse, phage display, single domain antibodies

\section{A Corrigendum on}

Genetic Removal of the CH1 Exon Enables the Production of Heavy Chain-Only IgG in Mice by Zhang, T., Cheng, X., Yu, D., Lin, F., Hou, N., Cheng, X., et al. (2018). Front. Immunol. 9:2202. doi: $10.3389 /$ fimmu.2018.02202

In the original article "Janssens R, et al., Generation of heavy-chain-only antibodies in mice. Proc Natl Acad Sci USA. (2006) 103:15130-35" was not cited. The citation has now been inserted in the Discussion, paragraph one, and should read:

"Naturally, HcAbs, which show great potential in many applications such as laboratory practice, analysis of small chemicals, clinical diagnosis, and therapeutic applications (17, 44-49), are found in camelids and sharks. In this study, we set out to investigate whether the precise genetic removal of the $\mathrm{CH} 1$ exon from an IgG-encoding gene would enable the production of functional HcAbs in mice. Using gene targeting technology, we generated a mouse line in which the $\gamma 1$ $\mathrm{CH} 1$ exon was deleted, and although these mice expressed heavy chain-only IgG1, they mounted only a weak IgG1-specific response when immunized with particular antigens. We were able to isolate antigen-specific single VH domain antibodies from these mice, although these antibodies exhibited a lower antigen binding affinity than conventional monoclonal antibodies. Therefore, this study reveals the possibility of using genetically modified small laboratory animals to produce monoclonal single $\mathrm{VH}$ domain antibodies. Attempts to produce heavy chain only antibodies in mice have previously been reported. For example, using $\mu \mathrm{MT}$ mice, Janssens et al. have generated transgenic mice containing hybrid chimeric loci, where non-rearranged llama VHH exons were linked with $\mathrm{CH} 1$ exon-removed human $\mathrm{IgH}$ constant region genes (50). These mice were shown to be able to produce chimeric llama-human heavy chain only antibodies. In this study, we set out to investigate whether fully murine heavy chain only antibodies could be produced if we remove the $\mathrm{CH} 1$ exon of endogenous mouse $\gamma 1$ constant region gene precisely via gene targeting."

The authors apologize for this error and state that this does not change the scientific conclusions of the article in any way. The original article has been updated. 


\section{REFERENCES}

50. Janssens R, Dekker S, Hendriks RW, Panayotou G, van Remoortere A, San JK, et al. Generation of heavy-chain-only antibodies in mice. Proc Natl Acad Sci USA. (2006) 103:15130-35. doi: 10.1073/pnas.06011 08103
Copyright (๑ 2019 Zhang, Cheng, Yu, Lin, Hou, Cheng, Hao, Wei, Ma, Fu, Ma, Ren, Han, Yu, Yang and Zhao. This is an open-access article distributed under the terms of the Creative Commons Attribution License (CC BY). The use, distribution or reproduction in other forums is permitted, provided the original author $(s)$ and the copyright owner(s) are credited and that the original publication in this journal is cited, in accordance with accepted academic practice. No use, distribution or reproduction is permitted which does not comply with these terms. 